\title{
Myocardial Protection with Beta Blocker Treatment in Infants with Heart Failure Due to Congenital Heart Defects and Duchenne Muscular Dystrophy
}

\author{
Buchhorn Reiner ${ }^{1,2}$ \\ ${ }^{1}$ Department of Pediatrics, Caritas-Krankenhaus Bad Mergentheim, Bad Mergentheim, Germany \\ ${ }^{2}$ Medical Faculty, University of Wuerzburg, Würzburg, Germany \\ Email: buchrein@gmail.com
}

How to cite this paper: Reiner, B. (2020) Myocardial Protection with Beta Blocker Treatment in Infants with Heart Failure Due to Congenital Heart Defects and Duchenne Muscular Dystrophy. Open Journal of Thoracic Surgery, 10, 81-88. https://doi.org/10.4236/ojts.2020.104008

Received: December 6, 2020

Accepted: December 28, 2020

Published: December 31, 2020

Copyright $\odot 2020$ by author(s) and Scientific Research Publishing Inc. This work is licensed under the Creative Commons Attribution International License (CC BY 4.0).

http://creativecommons.org/licenses/by/4.0/

\section{(c) (i) Open Access}

\begin{abstract}
Our first intention to treat infants' heart failure with beta blockers was to improve the clinical condition as shown in our prospective randomized trial. We only use non-selective beta blockers in these infants, carvedilol in those with left ventricular dysfunction and propranolol in those with congenital heart disease without ventricular dysfunction. Despite a significant improvement of Ross's heart failure score, we could not convince most colleagues within the last 25 years if the concept of neurohumoral activation in heart failure is not well-established pediatric cardiology. Recently, Honghai Liu et al. published that cardiomyocyte cytokinesis failure was increased in congenital heart disease. Inactivation of the beta adreno receptors genes and administration of the beta-blocker propranolol increased cardiomyocyte division in neonatal mice, which increased the number of cardiomyocytes (endowment) and conferred benefit after myocardial infarction in adults. We currently realize that propranolol in infants with congenital heart disease not only decrease highly elevated NT-Pro-BNP values but also decrease cardiac troponin $\mathrm{T}$ values that may indicate myocardial injury due to neurohumoral activation. We reproduce this observation, primarily seen in infants with congenital heart disease, in an infant with Duchenne muscular dystrophy. These observations were in good accordance with current data from $\mathrm{H}$. Liu et al., who showed that treatment with non-selective beta blockers early after birth might rescue cytokinesis defects and prevent heart dysfunction in adulthood in a mouse model.
\end{abstract}




\section{Keywords}

Heart Failure, Congenital Heart Disease, Duchenne Muscular Dystrophy, Propranolol, Carvedilol, Cardiac Troponin T, Myocardial Injury

\section{Introduction}

Recently, H. Liu et al. showed that treatment with non-selective beta blockers early after birth might rescue cytokinesis defects in infants with congenital heart defects and prevent heart dysfunction in adulthood in a mouse model [1].

The efficacy of beta blockers for the treatment of adult heart failure is well established. However, there are currently no guidelines for the use of beta blockers, such as propranolol, to treat heart failure in infants with congenital heart disease despite significant supporting evidence for the clinical use [2].

Based upon 25 years' experience with beta blocker treatment in infants with heart failure due to congenital disease, I will now discuss three clinical cases that show that myocardial protection in early infancy with propranolol and carvedilol treatment may prevent myocardial injury in infants with heart failure due to congenital heart disease or Duchenne muscular dystrophy.

\section{Methods}

\subsection{Processing and Analysis of 24-Hour-Holter Recordings}

The infants are routinely monitored with our Dräger Infinity Monitors ${ }^{\mathrm{TM}}$ (Dräger; Germany). For analysis of heart rate variability we export the monitor data to the Pathfinder ${ }^{\mathrm{TM}}$ ECG Software using a network connection. All Holter recordings were reviewed by an experienced cardiologist and were edited to validate the system's QRS labeling in order to exclude artifacts. Measures of heart rate variability were calculated employing only normal to normal intervals. The Holter ECG's were analyzed as average values from the entire 24 hours of analyzable data. For this publication, we only use frequency domain measures if the time domain measures have very low values in neonates and cannot differentiate the changes of the autonomic tone.

\subsection{Frequency Domain Measures}

Measurement and physiological interpretation of heart rate variability parameters were performed according to the standards of the Task Force of the European Society of Cardiology and the North American Society of Pacing and Electrophysiology. Beat-to-beat fluctuations were transformed to the frequency domain using Fast Fourier Transformation. Spectral power was determined over three frequency regions of interest: very low frequency power (VLF, $0.004-0.04$ $\mathrm{Hz}$ ), low frequency power $(\mathrm{LF}, 0.04-0.15 \mathrm{~Hz})$ and high frequency power (HF, $0.15-0.4 \mathrm{~Hz}$ ). High frequency power reflects mostly vagal tone. 


\section{Case 1: Pre- and Postoperative Management of an Infant with Severe Heart Failure Due to a Truncus Arteriosus Communis}

This case is illustrated in Figure 1. This neonate suffered from severe heart failure due to pulmonary over circulation of cause a truncus arteriosus communis despite a pharmacotherapy with metoprolol, spironolactone, and hydrochlorothiazide. Cardiac surgeons refused immediate operation because of low birth weight of $2400 \mathrm{~g}$ but despite nasogastric tube there was no weight gain. We decide to change the cardio selective beta blocker metoprolol $(0.5 \mathrm{mg} / \mathrm{kg})$ to 2 $\mathrm{mg} / \mathrm{kg}$ propranolol. Further we introduce digoxin and observe an improvement of heart rate variability indicated by the power spectrum of the Fast Fourier Analysis and a further decrease of average heart rate to the target heart rate of $125 \mathrm{bpm}$. Due to improved weight gain she had successful cardiac surgery with $3.5 \mathrm{~kg}$ bodyweight. Highly elevated NT-BNP and cardiac cTnT drop down after changing from metoprolol to propranolol. After corrective surgery she suffers from severe heart failure again, treated with sildenafil, frusemide, hydrochlorothiazide, spironolactone, and digoxin. We switched again to propranolol step by step and could exclude all other drugs. Again NT-BNP and cardiac cTnT decrease and heart rate variability increase. The complete recovery is illustrated by the steep increase of heart rate variability after 75 days. The clinical improvement is clearly shown by a decrease of highly elevated NT-Pro-BNP and cardiac Troponin (CTnT) values.

\section{Case 2: Pre-Operative Management of an Infant with Down's Syndrome and Severe Heart Failure Due to a Ventricular Septal Defect and Left Ventricular Dysfunction}

This case is illustrated in Figure 2. We started carvedilol in this neonate with Down's syndrome and ventricular septal defect with a very high NT-Pro BNP value of $101,000 \mathrm{pg} / \mathrm{ml}$ (Figure 2 was illustrated with NT-BNP in $\mathrm{ng} / \mathrm{ml}$ ) who was treated with dobutamine due to left ventricular dysfunction. We could stop dobutamine after 24 hours while HRV increase to normal values within one week and NT-Pro BNP decrease rapidly. Myocardial injury was indicated by cTnT levels up to $125 \mathrm{ng} / \mathrm{ml}$ who drop down to normal after the switch to carvedilol. The baby could be quickly weaned from ventilator and complete breastfeeding was established at the time of admission after 2 weeks. Ventricular dysfunction recover to normal measured by echocardiography. Up to the successful operation while treated with $0.7 \mathrm{mg} / \mathrm{kg}$ carvedilol, he was free of clinical heart failure with normal weight gain. The baby was successfully operated at the age of six month.

\section{Case 3: Neonatal Heart Failure Due to Duchenne's Muscular Dystrophy}

This case is illustrated in Figure 3. The boy was born with muscle weakness and 
heart failure and need gastric tube feeding. Based upon elevated NT-BNP and cTnT values, we anticipate a neonatal myocarditis and start treatment with carvedilol after one week and observed a quick improvement of his clinical condition. However, later we receive the genetic results that show Duchenne's muscular dystrophy. We decide for ongoing carvedilol treatment for myocardial protection of cause ongoing elevated cTnT values. At the age of 4 years, he is in an optimal clinical condition.

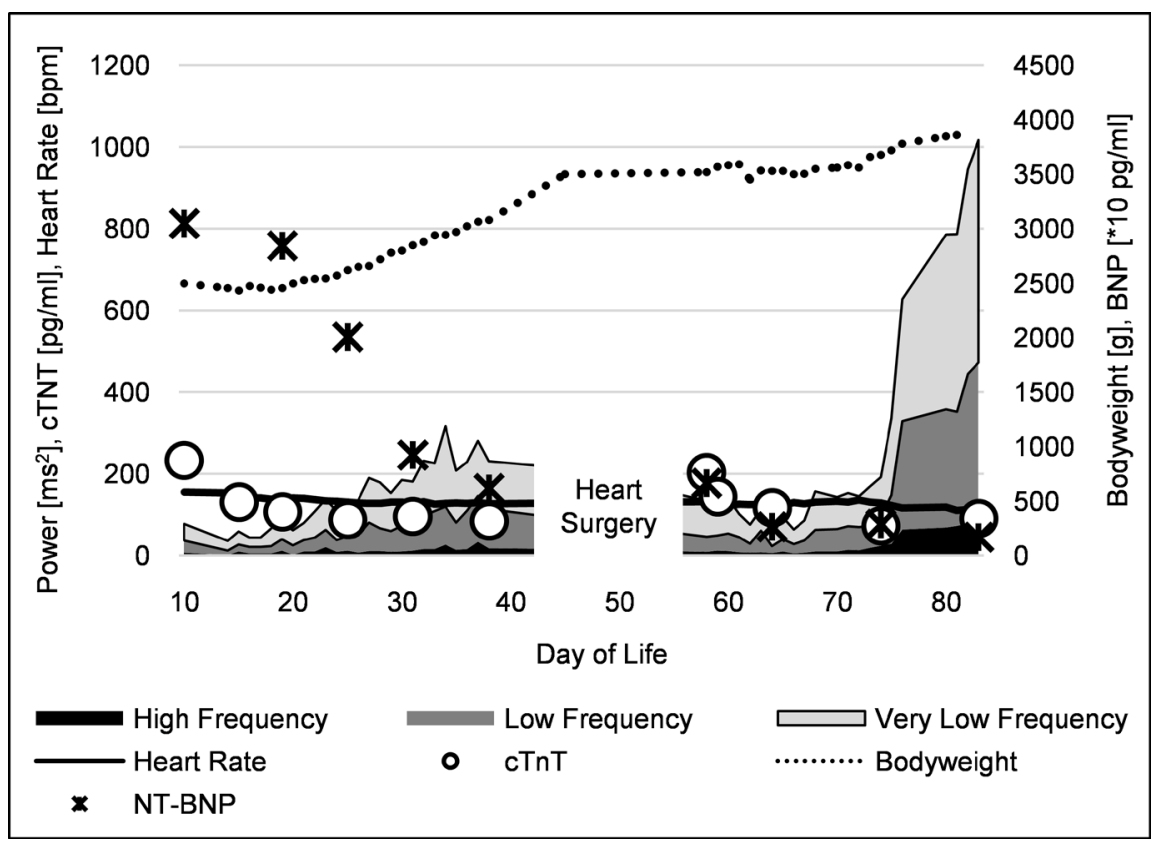

Figure 1. Pre- and postoperative management of an infant with severe heart failure due to a truncus arteriosus communis.

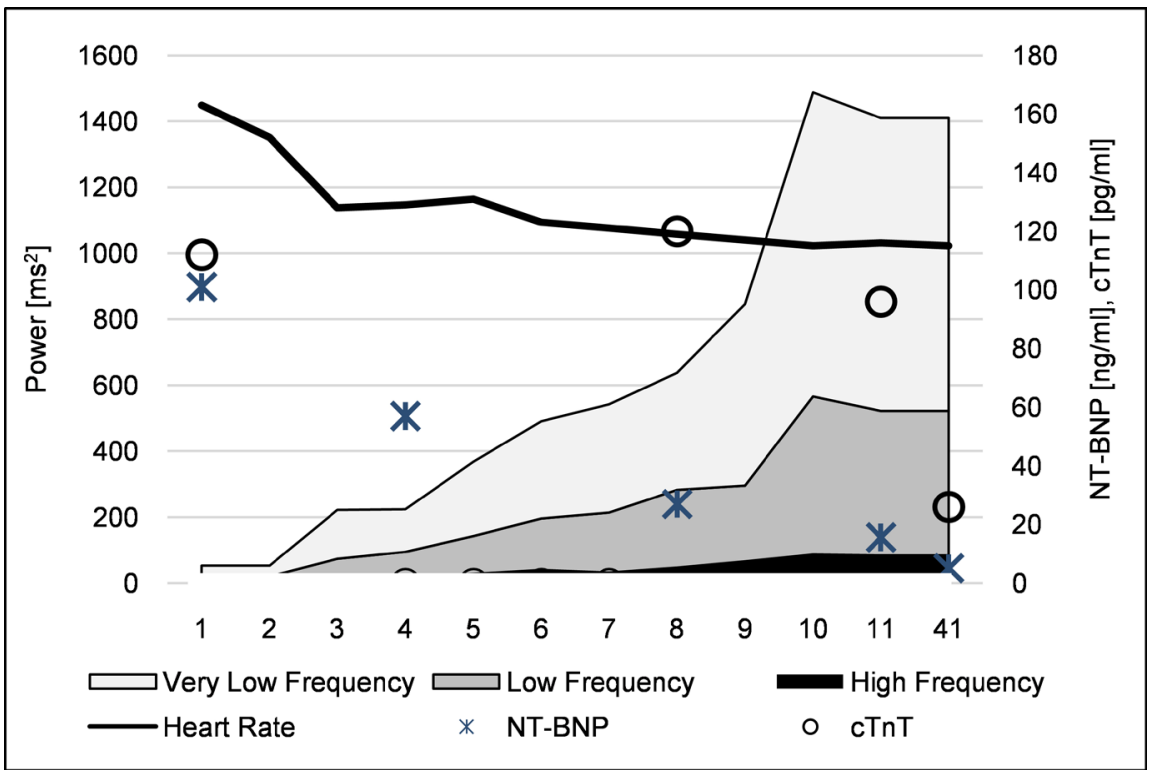

Figure 2. Pre-operative management of an infant with Down's syndrome and severe heart failure due to a ventricular septal defect and left ventricular dysfunction. 


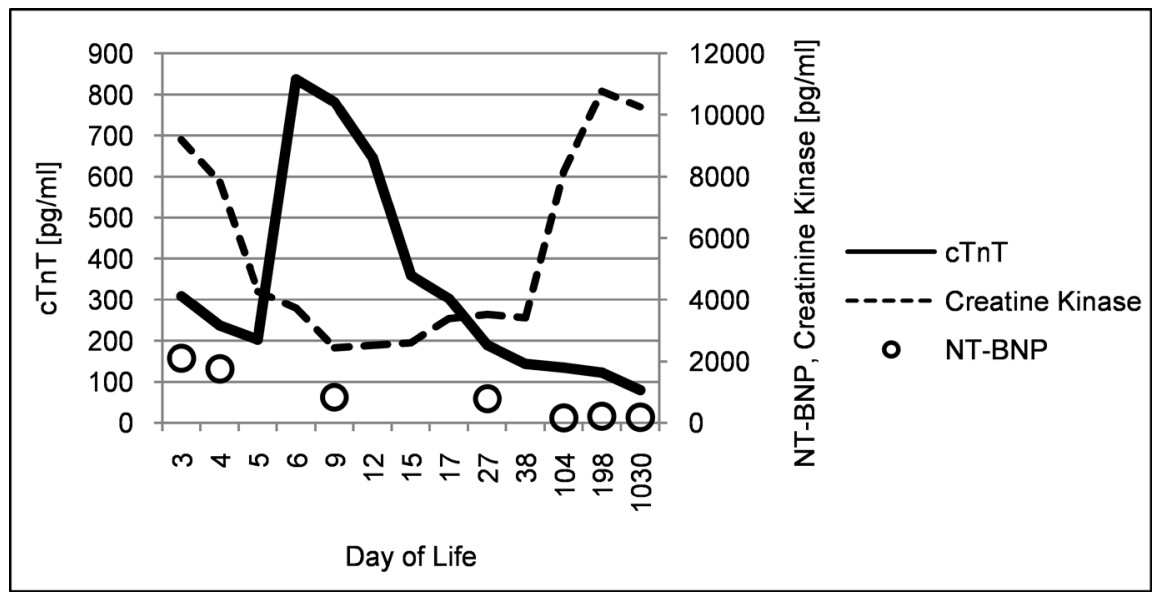

Figure 3. Neonatal heart failure due to Duchenne's muscular dystrophy.

\section{Discussion}

Elevated cardiac troponin $\mathrm{T}(\mathrm{cTn} \mathrm{T})$ is a specific marker of myocardial injury not only in most of all adults with myocardial infarction but also in patients with heart failure and congenital heart disease, even in newborns [3]. However, healthy neonates have higher cTnT values up to $100 \mathrm{pg} / \mathrm{ml}$ [4] compared to healthy adults $(<14 \mathrm{pg} / \mathrm{ml})$.

CTnT has been investigated as a prognostic marker and is a strong and independent predictor of all-cause and cardiovascular mortality, and of hospitalization for cardiovascular causes in patients with chronic heart failure [5]. Two recently published studies confirm the prognostic value of elevated cTnT level in children with congenital heart disease [6] [7].

The reason for elevated $c \operatorname{TnT}$ in infants with congenital heart disease is unknown, but it seems to be related to neurohormonal activation as shown by highly elevated norepinephrine values [8].

Beta blockers have protective effects against myocardial injury in patients with congestive heart failure [9] and protect these patients against elevated cTnT [10]. In infants with congenital heart disease, propranolol treatment improves diastolic ventricular function, indicated by significantly lower left atrial pressures, lower end-diastolic pressures, and less pronounced ventricular hypertrophy. The latter is estimated by lower ratios of myocardial wall to ventricular cavity areas on average of $42 \%$ [11]. In those infants treated with digoxin and diuretics, there was a significant down-regulation of beta2-receptor and angiotensin-2 receptor genes, and up-regulation of endothelin a receptor and connective tissue growth factor genes, which were partially prevented by additional treatment with propranolol. These data from the prospective CHF-Pro-Infant trial indicate a beneficial cardiac remodeling in propranolol treated infants as published in 2003 [13].

Furthermore, $\mathrm{cTnT}$ is further chronically elevated in patients with skeletal myopathies [12] and may be used for accurate evaluation of Duchenne cardiomyopathy [13]. Time course of cTnT elevations in children with Duchenne 
muscular dystrophy in comparison to myocarditis are published [14].

Our first intention to treat infants' heart failure with a beta blocker was to improve the clinical condition as shown in a prospective randomized trial [2]. We only use non-selective beta blockers in these infants, carvedilol in those with left ventricular dysfunction and propranolol in those with congenital heart disease without ventricular dysfunction. As shown in the three cases, we now realize that non-selective beta blockers but not metoprolol (see case 1) additionally decrease elevated cTnT values in infants with heart failure. We do not know if cTnT levels decrease of cause improving heart failure indicated by lower NT-BNP values or due to a direct myocardial protection against the cardiotoxic effects of highly elevated norepinephrine levels. However, the current data published from $\mathrm{H}$. Liu et al., who showed that treatment with non-selective beta blockers early after birth might rescue cytokinesis defects and prevent heart dysfunction in adulthood in a mouse model, strongly support our therapeutic approach to prevent the loss of myocardium due to early life stress by propranolol or carvedilol treatment.

We wonder why 33 years after RD Ross report about highly elevated norepinephrine levels in children with congenital heart disease [8], 22 years after our first report of an clinical improvement after propranolol in infants with severe heart failure [15] and 19 years after DJ Evans report about the impact of elevated norepinephrine levels on neurodevelopmental outcome in preterms [16], no further study proof if beta blockers may protect the heart and/or the brain against early life stress induced damages [17].

In conclusion, the recently published data about the impact of propranolol on increased cytokinesis failure in congenital heart disease from H. Liu et al. [1] together with our data who show myocardial protection by the decrease of cTnT after propranolol or carvedilol treatment are very important to increase the acceptance of early beta blocker therapy in infants with heart failure and other infants who suffer from early life stress to improve longtime cardiovascular health. The decrease of highly elevated cTnT after carvedilol in an infant with Duchenne muscular dystrophy may eventually prevent the cardiomyopathy that have a high impact on prognosis.

\section{Conflicts of Interest}

The author declares no conflicts of interest regarding the publication of this paper.

\section{References}

[1] Liu, H., Zhang, C.H., Ammanamanchi, N., Suresh, S., Lewarchik, C., Rao, K., et al. (2019) Control of Cytokinesis by $\beta$-Adrenergic Receptors Indicates an Approach for Regulating Cardiomyocyte Endowment. Science Translational Medicine, 11, eaaw6419. https://doi.org/10.1126/scitranslmed.aaw6419

[2] Buchhorn, R., Hulpke-Wette, M., Hilgers, R., Bartmus, D., Wessel, A. and Bursch, J. (2001) Propranolol Treatment of Congestive Heart Failure in Infants with Conge- 
nital Heart Disease: The CHF-PRO-INFANT Trial. Congestive Heart Failure in Infants Treated with Propanol. International Journal of Cardiology, 79, 167-173. https://doi.org/10.1016/S0167-5273(01)00413-2

[3] Neves, A.L., Cabral, M., Leite-Moreira, A., Monterroso, J., Ramalho, C., Guimaraes, H., et al. (2016) Myocardial Injury Biomarkers in Newborns with Congenital Heart Disease. Pediatrics and Neonatology, 57, 488-495.

https://doi.org/10.1016/j.pedneo.2015.11.004

[4] Tarkowska, A. and Furmaga-Jablonska, W. (2012) The Evaluation of Diagnostic Role of Cardiac Troponin T (cTnT) in Newborns with Heart Defects. The Scientific World Journal, 2012, Article ID: 682538. https://doi.org/10.1100/2012/682538

[5] Aimo, A., Januzzi Jr., J.L., Vergaro, G., Ripoli, A., Latini, R., Masson, S., et al. (2018) Prognostic Value of High-Sensitivity Troponin T in Chronic Heart Failure: An Individual Patient Data Meta-Analysis. Circulation, 137, 286-297. https://doi.org/10.1161/CIRCULATIONAHA.117.031560

[6] Abiko, M., Inai, K., Shimada, E., Asagai, S. and Nakanishi, T. (2018) The Prognostic Value of High Sensitivity Cardiac Troponin $\mathrm{T}$ in Patients with Congenital Heart Disease. Journal of Cardiology, 71, 389-393.

https://doi.org/10.1016/j.jjcc.2017.09.012

[7] El-Amrousy, D., Hassan, S. and Hodeib, H. (2018) Prognostic Value of Homocysteine and Highly Sensitive Cardiac Troponin $\mathrm{T}$ in Children with Acute Heart Failure. Journal of the Saudi Heart Association, 30, 198-204.

https://doi.org/10.1016/j.jsha.2017.11.007

[8] Ross, R.D., Daniels, S.R., Schwartz, D.C., Hannon, D.W., Shukla, R. and Kaplan, S. (1987) Plasma Norepinephrine Levels in Infants and Children with Congestive Heart Failure. The American Journal of Cardiology, 59, 911-914.

https://doi.org/10.1016/0002-9149(87)91118-0

[9] Toyoda, S., Haruyama, A., Inami, S., Amano, H., Arikawa, T., Sakuma, M., et al. (2017) Protective Effects of Bisoprolol against Myocardial Injury and Pulmonary dysFunction in Patients with Chronic Heart Failure. International Journal of Cardiology, 226, 71-76. https://doi.org/10.1016/j.ijcard.2016.10.046

[10] Pascual-Figal, D.A., Manzano-Fernandez, S., Pastor, F., Garrido, I.P., Casas, T., Sanchez, Mas. J., et al. (2008) [Troponin-T Monitoring in Outpatients with Nonischemic Heart Failure]. Revista Espanola de Cardiologia, 61, 678-686. https://doi.org/10.1157/13123988

[11] Buchhorn, R., Hulpke-Wette, M., Ruschewski, W., Ross, R.D., Fielitz, J., Pregla, R. et al. (2003) Effects of Therapeutic Beta Blockade on Myocardial Function and Cardiac Remodelling in Congenital Cardiac Disease. Cardiology in the Young, 13, 36-43. https://doi.org/10.1017/S1047951103000076

[12] Schmid, J., Liesinger, L., Birner-Gruenberger, R., Stojakovic, T., Scharnagl, H., Dieplinger, B., et al. (2018) Elevated Cardiac Troponin T in Patients with Skeletal Myopathies. Journal of the American College of Cardiology, 71, 1540-1549. https://doi.org/10.1016/j.jacc.2018.01.070

[13] Matsumura, T., Saito, T., Fujimura, H. and Shinno, S. (2007) Cardiac Troponin I for Accurate Evaluation of Cardiac Status in Myopathic Patients. Brain \& Development, 29, 496-501. https://doi.org/10.1016/j.braindev.2007.01.009

[14] Zhang, Y., Wang, H., Yu, X., Xing, Y., Wang, C. and He, R. (2016) Comparison Analysis of Muscle Enzymes in Children with Myocarditis and Duchene/Becker Muscular Dystrophy. Journal of Central South University Medical Sciences, 41, 984-991. 
[15] Buchhorn, R., Bartmus, D., Siekmeyer, W., Hulpke-Wette, M., Schulz, R. and Bursch, J. (1998) Beta-Blocker Therapy of Severe Congestive Heart Failure in Infants with Left to Right Shunts. The American Journal of Cardiology, 81, 1366-1368. https://doi.org/10.1016/S0002-9149(98)00175-1

[16] Evans, D.J., MacGregor, R.J., Dean, H.G. and Levene, M.I. (2001) Neonatal Catecholamine Levels and Neurodevelopmental Outcome: A Cohort Study. Archives of Disease in Childhood Fetal and Neonatal Edition, 84, F49-F52.

https://doi.org/10.1136/fn.84.1.F49

[17] Buchhorn, R. (2019) Neurodevelopment after Critical Illness in Infancy: Stress-The Big Forgotten Player. EC Cardiology, 6, 398-406. 